\title{
Razón pública y derechos fundamentales En diálogo con John Rawls
}

\author{
Javier López de Goicoechea Zabala \\ Universidad Complutense de Madrid
}

RESUMEN: El autor revisa la teoría de la justicia de John Rawls, la cual, en su opinión, es una concepción solidaria del liberalismo contractualista. En el artículo se plantea sobre la vinculación de los derechos humanos en la razón pública. Aquí se recoge la polémica sobre las relaciones entre esa razón pública y lo que el propio Rawls denomina razones comprehensivas. En el artículo se aborda cómo se vinculan esas razones comprehensivas con la razón pública o política, en su sistema procedimental para una sociedad justa.

ABSTRACT: The author reviews John Rawls' theory on justice, which, in his opinion, is a solidary conception of contractualist liberalism. In this work, the author poses the links of human right and public reason. The author also reviews the debate on the relations of public reason and what Rawls himself called comprehensive reasons. The essay focuses on the links between those comprehensive reason ant the public or politic reason, in its procedimental system for a fair society.

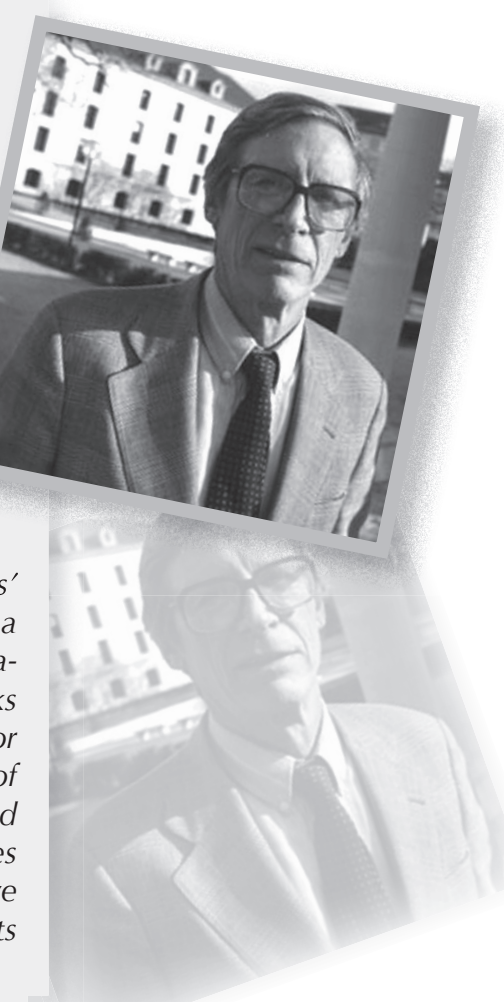


ohn Rawls, recientemente fallecido y uno de los más importantes teóricos del pensamiento político del siglo XX, nos legó un impresionante sistema procedimental acerca de la justicia, que podríamos resumir en una concepción solidaria y cooperante del liberalismo contractualista. Sin embargo, muchos teóricos del liberalismo posesivo, otros muchos desde el comunitarismo e, incluso, desde sus mismas filas kantianas del dialogismo racional, han ido marcando dificultades y problemas en la aplicación práctica de dicho sistema. Una de las cuestiones más debatidas desde las diferentes tradiciones es el encaje de las diversas formas de entender el contenido duro de los Derechos Humanos o Derechos Fundamentales en el entramado de la pura razón pública. En definitiva, se trata de la vieja polémica sobre las relaciones entre esa razón pública y lo que el propio Rawls denomina razones comprehensivas, aunque ahora desde un prisma más abierto, en línea con lo que las declaraciones internacionales de derechos reclaman. Veamos, por tanto, cómo encajan esas razones comprehensivas con lo que viene denominándose como razón pública o política, en su sistema procedimental para una sociedad justa.

\section{Derechos Fundamentales y diversidad cultural}

1 no de los debates más intensos y prometeicos que se han producido en la filosofía jurídica de los últimos cincuenta años es, sin duda, el de la fundamentación de los llamados Derechos Humanos o Derechos Fundamentales, partiendo del convencimiento asumido de que existe una diversidad de cosmovisiones comprehensivas del mundo y que, por tanto, resulta imposible articular un discurso de máximos, aunque nos encontremos ante uno de los asuntos cruciales para la salvaguarda de la dignidad de los seres humanos. Si adoptásemos una actitud fenomenológica, enseguida podríamos comprobar cómo principios que para una gran mayoría de la humanidad son incontrovertibles, aunque luego puedan ser salvajemente mancillados, como por ejemplo la mencionada dignidad intrínseca de cualquier ser humano, resulta un principio inferior en culturas donde la vida humana no cuenta con el referente kantiano de ser un fin, sino más bien al contrario un mero medio al servicio de otros elementos sistémicos de coloración política, social o religiosa. Y es ante este panorama que nos debemos preguntar, una y otra vez, por las razones 
que fundamentan la singularidad $y$ preeminencia de principios que podamos verdaderamente apuntalar como goznes inquebrantables de la universalidad del Derecho.

Pero sabemos que cualquier fundamentación racional de principios ético-jurídicos debe pasar por el tribunal de la eficacia de los mismos, puesto que de nada servirían hermosos principios poéticamente expresados en solemnes declaraciones universales que finalmente solo fueran meros remedos de un catecismo moral para ciudadanos bienpensantes. Por eso se hace urgente la teséica tarea, como sostiene Delgado Pinto, de caracterizar sin complejos a los derechos fundamentales como aquellas exigencias de justicia, formulables como derechos de individuos y grupos, que en cada momento histórico se considera que deben quedar reconocidos y amparados en la Constitución propia de cada comunidad política, sustrayéndose al arbitrio del poder ordinario de gobierno ${ }^{1}$.

El problema, como hemos apuntado ya, es cómo determinar, partiendo del postulado kantiano de la dignidad absoluta del individuo, cuáles son esas exigencias que cabe considerar como Derechos Humanos en cada momento histórico y cultural. De nada nos sirve, a nuestro juicio, un discurso intuicionista, puesto que el orden moral objetivo de derechos y deberes estaría siempre al albur de la intuición propia de cada individuo y de cada sociedad, cayendo en un relativismo crónico inservible para cuestión tan importante. Tampoco nos vale de nada cualquier tipo de discurso monológico sustentado en algún tipo de autoridad moral, puesto que son fruto de la historia y de sus coyunturas temporales, por lo que tan sólo valdrían para salvaguardar un cierto orden fundamental durante cierto tiempo tasado abocado a consumirse. Por tanto, siguiendo de nuevo a Delgado Pinto, parece que la única forma de fundamentación razonable y realista de los principios fundamentales relativos a los Ilamados Derechos Humanos, radica en el acuerdo alcanzado a través de un proceso de deliberación debidamente articulado, de todos los componentes de un grupo social que establezcan las condiciones básicas de su cooperación. Se trataría de un acuerdo falible, cuya racionalidad estará siempre y por principio sujeta a revisión ${ }^{2}$.

Este acuerdo racional, falsable y deliberativo, en el sentido aristotélico del discurso, debe partir siempre, como advierte Apel, del reconocimiento del derecho de los restantes miembros de la comunidad deliberativa a mantener sus propias posiciones y defenderlas con argumentos racionales ${ }^{3}$; o como también destaca Habermas, sólo se puede llevar a cabo desde el recíproco reconocimiento y simetría entre todos los interlocutores ${ }^{4}$. Es decir, debemos partir del postulado previo de que el ciudadano es todo ser humano dotado de compe- 
tencia comunicativa, con capacidad de diálogo racional y capacidad de dominio de los universales constitutivos del diálogo, en expresión de Adela Cortina $^{5}$.

Pues bien, si alcanzáramos la posibilidad de acuerdo sobre los a prioris de un diálogo comunicativo universal y en igualdad de condiciones, los postulados que de ahí saldrían deberían cumplir notas como las siguientes: ser derechos universales para todos, absolutos, innegociables, inalienables, derechos fuertes (ius cogens) y derechos que den lugar a crear las condiciones materiales que permitan dicha interlocución y las condiciones culturales que permitan decidir en pie de igualdad ${ }^{6}$. Esta pragmática formal de consenso acerca de lo que los hombres queremos quede a salvo de cualquier circunstancia o avatar histórico, debe ser tarea de todos los ciudadanos sin distinción de su condición económica, cultural o religiosa. Aunque, eso sí, a todos se les exigirá el máximo respeto a las reglas del juego, porque lo que no puede aceptarse es levantarse de la mesa y romper la partida, porque sencillamente nos jugamos todos demasiado en el empeño.

Por tal razón, como apunta Muguerza, uno de los imperativos desde los que tenemos que intentar razonar un discurso sobre los derechos fundamentales, es el imperativo de la disidencia que permitiera la posibilidad de decir "no" a situaciones en las que prevalecen la indignidad, la falta de libertad o la simple desigualdad. Esto nos con- duciría a un intento de fundamentación negativa o disensual de los derechos humanos, partiendo del hecho de que el disidente siempre será un sujeto individual y solitario que tome una decisión desde su propia conciencia disidente. Se trataría de admitir como imperativo fundamental que, ante lo que Horkheimer denominaba "mundo totalmente administrado", nos quedaría siempre la disidencia frente a la inhumanidad de las estructuras jurídicas y sociales, impidiendo, de esta forma, el vaciamiento postmoderno de cualquier discurso racional sobre los derechos fundamentales. Es decir, un disenso que sirva de dique de contención frente a los recientes intentos de hacer del discurso de los derechos del hombre un discurso retórico despojado de autenticidad y validez universal.

Pues bien, para evitar este reparto de los despojos de los derechos humanos, necesitamos un procedimiento sólido y contrastado que delimite perfectamente los parámetros del buen gobierno de los derechos fundamentales; buen gobierno que debe velar por su eficacia, sus garantías y, especialmente, por la seriedad de sus propuestas, en un último y desesperado intento por formalizar universalmente un auténtico criterio crítico-racional de validez e imposición de lo que consideremos como derechos fundamentales. Y ese test de legalidad fundamental nos lo proporciona la compleja pero insustituible propuesta procedimental que nos legó John Rawls. 


\section{El lugar público de los Derechos Fundamentales}

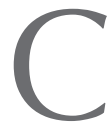

omo es sabido, el sistema rawlsiano articula un complejo sistema procedimental que busca la toma de decisiones justas, partiendo de la aceptación de la desigualdad inherente a nuestras sociedades, y siempre pensando en la ventaja de los más desfavorecidos en lo social y en lo económico. Dicho sistema vincula la consecución de unos principios de justicia pactados, con el logro de una sociedad más justa y solidaria, en donde la persona moral (autónoma, racional y cooperante) pueda desarrollar su vida individual y su propio plan existencial de forma plena. El punto de partida, por tanto, es el acuerdo sobre los mínimos de justicia para que todos puedan alcanzar ese plan de vida partiendo de la igualdad de oportunidades.

Para que se dé esta situación de principio, Rawls estipula una jerarquía de principios básicos, comenzando por el de igual libertad; siguiendo por el principio de igualdad de oportunidades; para acabar con el principio de diferencia a favor del más desfavorecido ${ }^{8}$. Esta articulación secuencial permite disponer a todos los ciudadanos de un mínimo común de libertad e igualdad básica, suficiente para poder, a partir de ahí, construir personal e intransferiblemente su propio plan de vida. Al final, como es lógico, las desigualdades primarias y naturales persisten, pero se activa el principio de diferencia para que a medida que la sociedad avance, lo haga beneficiando paso a paso a los que se sitúan en una posición de desventaja9 .

Pues bien, dentro de ese plan de vida por hacer, que cada ciudadano debería estar en disposición de emprender desde los mínimos de justicia, se encuentra la propia cosmovisión que cada cual tenga del mundo, de la realidad y de su propia vida. De ahí que Rawls no permita que los congregados a esa ficción jurídica prepolítica Ilamada posición original, accedan con su propia cosmovisión o razón comprehensiva de la realidad, puesto que sería un factor más de desequilibrio social ${ }^{10}$. Al final, el pacto político debe servir para todos, en condiciones de igualdad primigenia y bajo el duro cálculo egoísta de no verse perjudicados en el postrero reparto de la realidad social.

Para Rawls, el objeto de la justicia no puede ser otro que el de la estructura básica de la sociedad. Es decir, su sistema procedimental busca transformar paulatinamente dicha estructura social, intentando hacerla más justa, más igual y más solidaria. Y el sujeto de dicha justicia no serán, por tanto los individuos, sino las instituciones sociales, políticas y económicas, que son las que tienen que activar decisiones 
en cada ámbito desde los principios de igual libertad, igual oportunidad y diferencia a favor de los desfavorecidos. Tanto es así, que en su sistema no cabe la restricción de ninguna libertad o derecho básico, salvo que colisionen derechos fundamentales entre sí, momento en el que serán los jueces supremos (Tribunal Supremo o Corte Suprema Constitucional) quienes decidan, desde los principios de justicia, cuál de esas libertades básicas en conflicto en cada caso concreto resulta superior ${ }^{11}$.

Es más, en el ámbito internacional, donde también las ideas y las creencias religiosas juegan un papel fundamental de cara a alcanzar acuerdos de ámbito transnacional, dado que muchos países ajenos a la tradición ilustrada fundamentan sus sistemas jurídico-políticos internos en razones comprehensivas fuertes, pues bien, en este difícil ámbito los principios de justicia no deben, según Rawls, ser vencidos por la comodidad de la tolerancia mutua. Es decir, si no podemos llegar a acuerdos básicos sobre principios de justicia internacional, será mejor aceptar la situación de injusticia estructural que amagar con acuerdos que pisoteen tales principios. Es lo que denomina él mismo como utopía realista para el marco internacional de los principios de justicia. Es mejor, concluye, sostener una realidad injusta si al menos podemos conseguir cierto equilibrio de paz, que empeñarse en consolidar acuerdos imposibles dado que muchos países llegan a la posición original internacional cargados de razones comprehensivas propias que tratan de imponer a los demás. Es lo que Rawls Ilama acuerdos entre países decentes, incumplidores de los principios de justicia pero, al menos, no beligerantes con el resto ${ }^{12}$.

Rawls emplea el concepto 'político' diferenciado del concepto de 'metafísica' por lo siguiente: ser neutral frente a las distintas cosmovisiones o doctrinas comprehensivas de la realidad. Con este propósito, articula un consenso entrecruzado apropiado para los ciudadanos de una colectividad política plural en razones cosmovisivas: los ciudadanos dispuestos a vivir en una sociedad razonable (razón pública), adecuarán sus propias racionalidades comprenhensivas al marco común, asumiendo racionalmente sus consecuencias ${ }^{13}$.

Frente a las críticas de Habermas acerca del hecho de que nadie puede prescindir completamente de la propia precomprensión, por lo que partiremos siempre desde la perspectiva constituida por cada propia concepción del mundo, Rawls asume que los ciudadanos razonables tienen en cuenta desde el principio del pacto social que los otros también llegan al pacto originario como portadores de sus propias racionalidades comprehensivas: la razón pública, de hecho, se constituye cuando todos los miembros razonables de la sociedad incorporan sus propias concepciones comprehensivas a la común razón 
pública y no al revés ${ }^{14}$. Se trata de que, en igual libertad, cada uno marque su propia vida autodeterminada y auténtica.

Por tanto, no puede afirmarse que el sistema rawlsiano de justicia despoje al individuo de su componente cultural o religioso comprehensivo. Nada más lejos del pensamiento liberal democrático de nuestro autor. Lo que quiere Rawls es que los sistemas comprehensivos de la realidad, del tono que sean, admitan una prioridad en el devenir social que pasa por la implantación y actualización de los principios de justicia básicos. Es decir, la libertad de ideas y creencias, como manifestación jurídica de dichas cosmovisiones comprehensivas, será parte del tronco de mínimos de justicia, siempre que se someta a la jerarquía de tales principios: igual libertad/ igual oportunidad/diferencia para el desfavorecido. Si se admite esto, cualquier realidad comprehensiva puede y debe formar parte del núcleo duro de la razón pública. Es mas, para Rawls el ideal de una sociedad justa bien estructurada es que cualquier razón comprehensiva pueda coexistir sin problemas con el resto, coadyuvando al sostenimiento y actualización de los principios básicos ${ }^{15}$.

En definitiva, Rawls hace buena la máxima evangélica $A /$ César lo que es del César, y a Dios lo que es de Dios; es decir, a la razón pública lo que la constituye y a las realidades comprehensivas el amplio marco de realización personal de un plan de vida racional. Se trata, por tanto, de un dualismo procedimental, que no entra a valorar las virtudes, indiscutibles, del hecho intercultural y de las creencias en general, pero que prefiere resguardarse de tales cosmovisiones para asegurar antes los mínimos de convivencia en lo que denomina construcción de una razón pública. De hecho, como hemos visto, uno de los elementos imprescindibles en su sistema es la ficción jurídica de la posición original y del velo de la ignorancia, con el fin de que los reunidos ante el pacto político por excelencia, no tengan ningún tipo de información o tendencia que pueda enturbiar su decisión racional sobre lo que consideren justo.

\section{Conclusión: la razón (pública) y sus derechos}

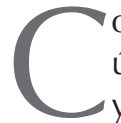

omo afirma Adela Cortina, la única forma de normalizar te la pluralidad cultural en nuestras sociedades, que describíamos como de ciudadanía compleja, es asumiendo que una sociedad laica debe permitir crecer en su seno a aquellas costumbres, creencias e ideas que cumplan los mínimos éticos requeridos, sin apostar por ninguna de ellas ${ }^{16}$. Es decir, será esa 
ciudadanía compleja la que acoja y asuma en su seno las diferentes creencias, cosmovisiones o formas de identidad cultural, dentro del principio de igualdad y de la falta de discriminación. El discurso de la dignidad, del diálogo, de la comunidad cosmopolita, de la igualdad y de la libertad de todos los seres humanos, así como el discurso de la santidad del ser humano, resulta un discurso de mínimos de justicia y de felicidad humana, es decir, de plenitud. Y esto entra de lleno en el reconocimiento del pleno desarrollo de la personalidad que amparan todos los textos universales de derechos, así como nuestros propios textos constitucionales.

Y para este libre y pleno desarrollo personal en el seno de una sociedad concreta, el hombre necesita un sistema de garantías firmemente asentadas, compartidas y respetadas, que respondan a su inquietud existencial y le permitan el libre desarrollo de lo que Rawls Ilamaría plan de vida. Algo que, recordábamos, aparece reflejado en todas las declaraciones de derechos fundamentales, como reconoce el artículo 29 de la Declaración Universal de Derechos Humanos de Naciones Unidas: "Toda persona tiene deberes respecto a la comunidad, puesto que sólo en ella puede desarrollar libre y plenamente su personalidad". Todos buscamos, pues, causas y principios desde los que explicar y dar cuenta de la realidad existente, suponiendo, además, pautas de comportamiento y significaciones simbólicas para la vida. El que unas respuestas respondan a paradigmas puramente científicos, naturalísticos, cosmológicos, sociales o personales, sólo dependerá del punto de partida de tales cosmovisiones. Pero todas ellas tienden a un mismo fin: situar al ser humano en la realidad, justificándolo frente a ella.

Desde este paradigma integrador y novedoso de lo comprehensivo como elemento conformador $y$ crítico del éthos social, es decir, de la praxis transformadora de la historia de los hombres, no cabe dibujar un marco jurídico comprensivo y encorsetado de una realidad tan viva y expansiva como la propia naturaleza compleja del ser humano. Materializar en un solo logos comprehensivo lo que significa para el hombre su dimensión simbólica y referencial sobre la realidad, más que un gesto prometeico supone un comportamiento corto de miras. Lejos de regular una realidad social, finalidad propia y laudable del Derecho, en este caso, estrangularía una realidad individual infinitamente más rica:

"A estas alturas ya no es necesario insistir en que la vida humana no es más que un puro fenómeno biológico cuando carece de sentido. La vida verdaderamente humana es una vida interpretada. A través del sentido que damos a la vida, interpretamos ésta y obtenemos, en vez de una maraña de sucesos, un ovillo ordenado y estructurado. Nos encontramos con una identidad en la vida, es decir, con la posibilidad de reconocer un sujeto. Pero éste no aparece ya dado desde un princi- 
pio, sino que tiene que construirse. Tenemos que encontrarnos a nosotros mismos mediante un sí mismo que halle coherencia en lo vivido. La vida individual aparece así como una historia que debe ser narrada"17

Sin embargo, este reconocimiento de aquello que supone nuclear para el plan de vida de cada cual, tiene su correlato inmediato y necesario en la plasmación de unos mínimos fundamentales y constituyentes, socialmente hablando, que nadie puede traspasar y que nadie debería poner en duda. Es el precio que debemos pagar por sostener un sistema de derechos inalienables, que Rawls resume en sus principios constitucionales. Tales principios no son negociables, porque ya han sido negociados y aceptados en la posición original. Y ni tan siquiera deben ser justificados o legitimados, porque ya lo han sido mediante el velo de la ignorancia y el principio maximin.

Por tanto, quedémonos con la doble reflexión que hemos recogido de uno de los grandes de la filosofía política del siglo XX, John Rawls, y definamos lo comprehensivo in suo ordine como la dimensión inviolable que cada ser humano tiene de realizar su propio plan de vida, una vez que la razón pública nos sitúe a todos en condiciones de igual ciudadanía, dispensando un trato preferencial hacia los más desfavorecidos. Y todo ello garantizado por esa convención constitucional, verdadero frontispicio de cualquier sociedad, también la internacional, que pretenda someterse, como decíamos al principio, al infranqueable tribunal rawlsiano de la justicia. De nada sirven las buenas intenciones o las grandes y retóricas declamaciones a favor del respeto a los principios que fundan los Derechos Humanos. Y de nada sirven porque cada cual siempre buscará el amparo de sus propias convicciones, sus propios usos culturales o sus propias experiencias históricas, vitales o socializadoras para hacer añicos cualquier consenso o acuerdo mutuo sobre estos aspectos. Sólo nos queda el sometimiento a las reglas del juego (igual libertad, igualdad de oportunidades y diferencia a favor de los desfavorecidos); y, una vez en el juego, el sometimiento a lo pactado. Es decir, con la razón pública (en el sentido rawlsiano del término) no se juega; y no se juega porque es la única garantía real que nos queda a los humanos para que nuestros derechos universales, el hilo que nos une todavía a la supervivencia y la dignidad a nivel planetario, no se mancillen ni se diluyan en la otra mesa de juego de nuestro mundo: el mercadeo entre Estados y el tráfico de intereses corporativos. 


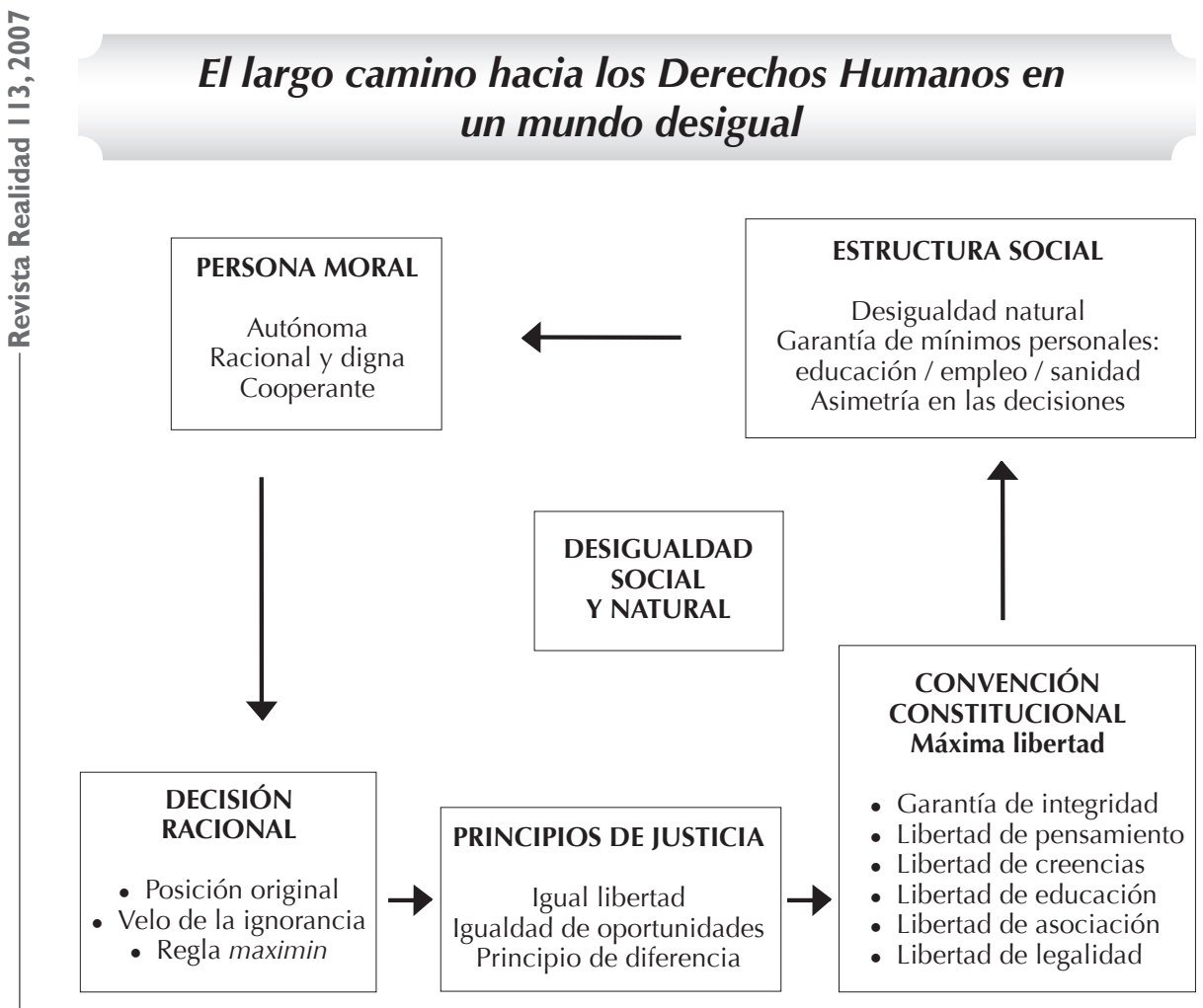

NoTAS

1 Delgado Pinto, J., "La función de los derechos humanos en un régimen democrático", en El fundamento de los derechos bumanos (J.Muguerza, Ed.), Madrid 1989, 135-153, p.137.

2 Ibíd., p.144.

3 Cf. Apel, K.O., La transformación de la filosofía, Madrid 1985, vol.II, pp.149 yss.

4 Cf. Habermas, J., Teoría de la Razón Comunicativa, vol. I, Madrid 1983, p.156 y ss.
5 Cf. Cortina, A., Razón comunicativa y responsabilidad solidaria, Salamanca 1985 , pp.70 y ss.

6 Id., "Pragmática formal y Derechos Humanos”, en El fundamento de los Derechos Humanos..., pp.131 y ss.

7 Muguerza, J., "La alternativa del disenso", en Ibidem, pp.43 y ss.

8 Cf. Rawls, J., El liberalismo político. Trad. A. Doménech, Barcelona 1996, pp. 247 y ss. 
9 Véase el cuadro final.

13 Ibíd., pp. 157 y ss.

10 Id. Teoría de la Justicia, Trad. Ma D.

14 Cf. Habermas, J. y Rawls, J., Debate González, México 1986, pp. 143 y ss.

11 Id., El liberalismo político, pp. 250 y ss. Véase el esquema circular que culmina el trabajo.

12 Id., El Derecho de Gentes y "Una revisión de la razón pública”, Trad. H. Valencia, Barcelona 2001, pp. 23 y ss. sobre el liberalismo político, Trad. G. Vilar, Barcelona 1998, pp. 147 y ss.

15 Ibíd., pp.75 y ss.

16 Cortina, A., Alianza y contrato. Política, ética y religión, Madrid 2001, pp. 174 y ss.

17 Ibíd., p.79. 